\title{
Intensification of UHF-therapy by an alternating magnetic field Zaharov M. ${ }^{1}$, Lahin V. ${ }^{2}$, Zaharov Ju. ${ }^{3}$, Smirnov A. ${ }^{4}$ (Russian Federation) Интенсификация УВЧ терапии переменным магнитным полем Захаров М. Ю. ${ }^{1}$, Лахин В. С. ${ }^{2}$, Захаров Ю. Б. ${ }^{3}$, Смирнов А. Б. ${ }^{4}$ (Российская Федерация)
}

\author{
I Захаров Михаил Юрьевич / Zakharov Mihail Jur'evich - дочент, \\ кафедра математики (и информатики), \\ Краснодарское высшее военное авиачионное училище летчиков; \\ 2 Лахин Владислав Сергеевич / Lakhin Vladislav Sergeevich - cтудент, \\ направление БТСиТ, \\ физико-технический факультет: \\ ${ }^{3}$ Захаров Юрий Борисович / Zakharov Yuri Borisovich - кандидат технических наук, дочент, \\ кафедра физики и информационных систем, \\ Кубанский государственный университет, \\ ${ }^{4}$ Смирнов Алексей Борисович / Smirnov Aleksej Borisovich-cuстемный администратор, \\ OOO «Статус», г. Краснодар
}

\begin{abstract}
Аннотация: в данной статье рассматривается новый способ интенсификации УВЧ терапии: добавление к переменному электрическому полю переменного магнитного поля. Данный метод позволит усилить терапевтический эффект процедуры, уменьшить время воздействия и многое другое. В статье изложена информация не только о самом методе, но и о его последствиях, способах применения и т. д. Abstract: this article describes a new way of intensification of UHF-therapy: adding an alternating magnetic field to variable electric field. This method will enhance the therapeutic effect of the procedure, reduce exposure time and more. The article provides information about process, consequences of it, various ways of use etc.
\end{abstract}

Ключевые слова: УВЧ-терапия, переменное электрическое поле, переменное магнитное поле, заряженные частицы, клетка, иитоплазма, движение ионов, разогрев.

Keywords: UHF-therapy, variable electric field, alternating magnetic field, charged particles, cell, cytoplasm, ion movement, warming-up.

Одним из наиболее распространенных электролечебных методов является воздействие на ткани организма токами ультравысокой частоты (25-50 МГц).

В действии высокочастотных колебаний традиционно различают две группы эффектов: тепловой и специфический эффект. Нагревание тканей токами и полями высокой частоты происходит не за счет передачи тепла, подведенного к поверхности тела, а за счет непосредственного выделения теплоты в расположенных внутри тела тканях и органах.

В аппаратах, реализующих методы УВЧ-терапии, электрическое поле создается с помощью двух конденсаторных электродов, соединенных проводами с генератором УВЧ-колебаний. Подвергаемая воздействию часть тела помещается между электродами. При внутриполостных воздействиях один из электродов вводится в соответствующую полость организма, а второй располагается около поверхности тела [1].

Результатом такого рода терапии является нагревание живых тканей, подвергающихся воздействию тока ультравысокой частоты. Выборочное лечение нужных областей тела пациента приводит к благоприятным эффектам разного рода: от снятия болевого синдрома и отека до влияния на работу нервной, кровеносной и многих других систем.

Классические аппараты УВЧ используют для воздействия на пациента только влияние переменного электрического поля, что, несомненно, хорошо. Но данное направление терапии явно нуждается в интенсификации.

Одним из возможных путей интенсификации является добавление постоянного магнитного поля. Этот вектор развития дает множество дополнительных преимуществ, но применяется лишь для лечения конечностей в посттравматические периоды, поскольку магнитное поле негативно влияет на внутренние органы человека [2].

УВЧ mepanuя

Частота от 24 до 41 МГц

УВЧ-терапия (ультравысокочастотная терапия; синоним ультракоротковолновая терапия) - метод лечения, заключающийся в воздействии на организм электрическим полем ультравысокой частоты (эп УВЧ), чаще с числом колебаний 40,68 МГц (длина волны 7,37 м), которое подводится к пациенту посредством конденсаторных пластин (электродов). При воздействии импульсами ЭП УВЧ (2-8 мксек), чередующимися с длинными паузами, метод называют импульсной УВЧ-терапией [10]. 


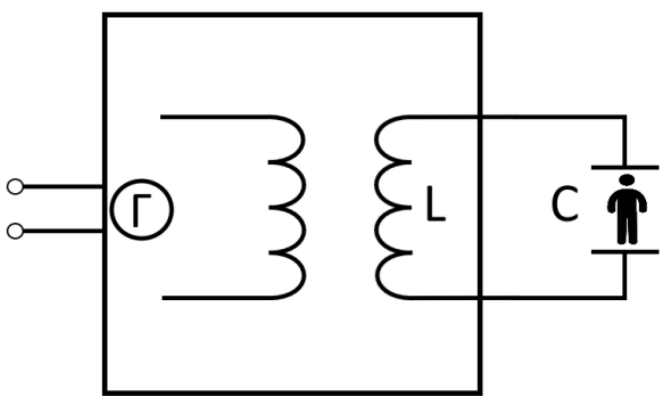

Puc. 1

Терапевтический колебательный контур (Г - генератор УВЧ).

Терапевтический контур не связан гальванически с генератором в целях защиты пациента от поражения током.

Лечебным фактором УВЧ-терапии является энергия ЭП УВЧ, поглощенная тканями организма. Терапевтическое действие ЭП УВЧ определяется не только образованием в тканях тепла, но и рядом физико-химических процессов в тканях организма, что лежит в основе местных и общих физиологических реакций. УВЧ-терапия благоприятно влияет на функциональное состояние нервной системы, эндокринных желез, крово- и лимфообращение, способствует улучшению обмена веществ. Этот метод лечения оказывает противовоспалительное, болеутоляющее, десенсибилизирующее, противоспастическое действие, стимулирует защитные силы организма и улучшает трофику тканей.

При проведении процедур УВЧ терапии конденсаторные пластины располагают параллельно поверхности тела пациента. Расстояние между малыми пластинами при их тангенциальном (т. е. на одной плоскости) расположении должно быть не менее их диаметра. Суммарная величина зазора (т. е. расстояние между телом пациента и конденсаторной пластиной) для первого и второго электрода не более 6 см. При малых зазорах плотность поля оказывается большей в поверхностных тканях по сравнению с глубокими. Для более равномерного воздействия на поверхностные и глубокие ткани зазор увеличивают.

Аппарат тщательно настраивают в резонанс. Размеры пластин должны соответствовать величине подвергаемого воздействию органа или участка тела. Процедуры продолжительностью от 5 до 20 мин. и более проводят два раза в день, ежедневно или через день, на курс лечения от 6 до 12 процедур, при необходимости курс лечения повторяют через 3-4 недели. УВЧ терапию проводят в положении больного сидя или лежа на деревянном кресле или кушетке через одежду больного. Наличие сухих гипсовых или марлевых повязок не служит препятствием для применения УВЧ терапии. Зазор создают с помощью сухих хлопчатобумажных тканей, войлока или фиксации пластин в заданном положении электрододержателями.

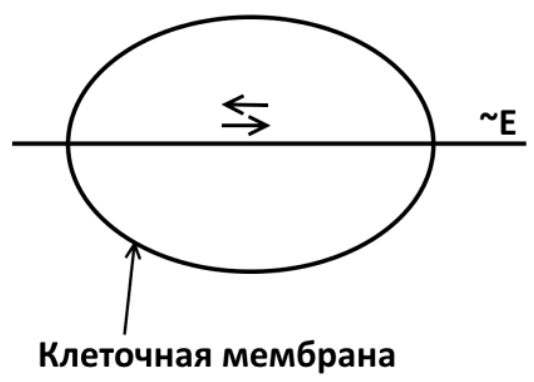

Puc. 2

На рис. 2 изображена модель живой клетки, через которую проходит переменное электрическое поле.

На ионы цитоплазмы действуют силы Кулона. Воздействуя на них переменным электрическим полем, в момент времени, когда вектор $\vec{E}$ направлен вправо, сила Кулона смещает «+» ион вправо, а «-» ион влево (рис. 3) [3]. При смене направления вектора $\vec{E}$, положительно заряженный ион стремится влево, а отрицательный - вправо. Поскольку весь цикл движений одного иона происходит очень быстро 
(зависит от используемой частоты в МГц), энергия колебаний ионов преобразуется в тепло и цитоплазма нагревается.

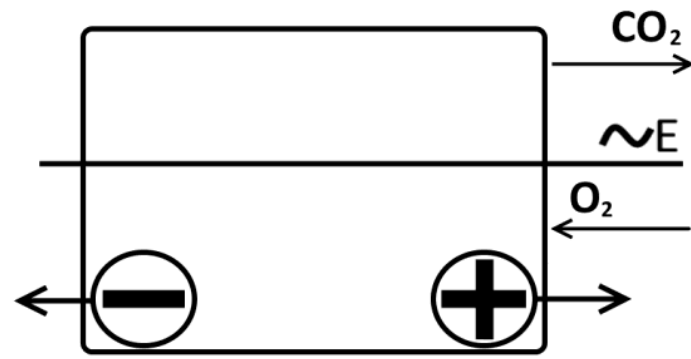

Puc. 3

В целом, УВЧ применяется довольно широко, но облучение не совсем полезно. Воздействие УВЧ на поврежденные конечности, как правило, занимает около 15 минут. Исчезновение болевого синдрома и отека наблюдается через 7-8 дней.

Интенсификация УВЧ терапии постоянным магнитным полем

Представим модельно клетку в виде параллелепипеда (рис. 4), где

- $\vec{B}$ - индукция магнитного поля

- $\quad$ Е - переменное электрическое поле

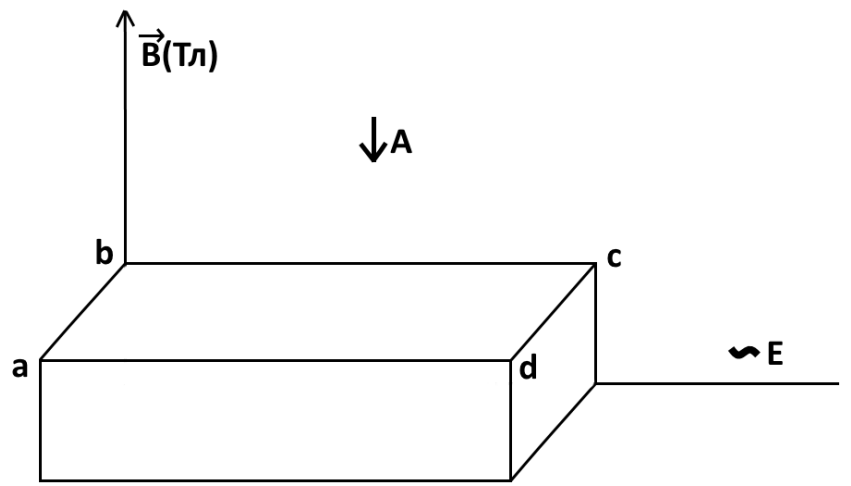

Puc. 4

Рассмотрим случай, когда линии магнитного поля направлены к нам, а вектор электрического поля вправо (рис. 5). Для этого будем считать, что клетка, изображеннная на рисунке 4, расположена к нам со стороны стрелки А, то есть смотрим мы на нее сверху. Под действием электрического поля (силы Кулона) возникает направленная скорость движения положительного иона вправо, а отрицательного влево. Поскольку клетка подвергается еще и магнитному воздействию, на заряженный ион действуют силы Лоренца, направленные перпендикулярно силе Кулона. Направление сил Лоренца определяется мнемоническим правилом левой руки. В дальнейшем будем рассматривать грань abcd [9]. 


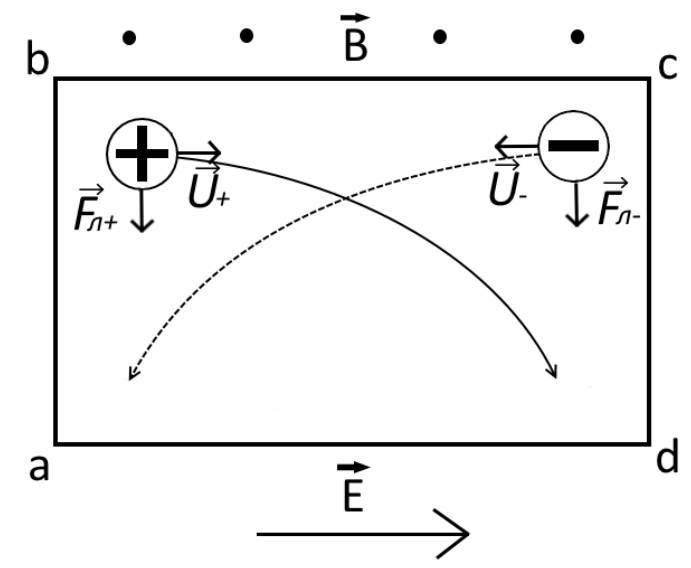

Puc. 5

$\vec{F}_{l}=q U B(\vec{U} \perp \vec{B})(1)[6]$,

$\overrightarrow{F_{\kappa}}=q \vec{E}=>\vec{U} \quad(2)[5]$,

$\vec{F}_{l} \perp \vec{F}_{\kappa}(3)$,

На рисунке 5 показано воздействие на ионы цитоплазмы следующих составляющих: постоянного электрического поля $\left(\overrightarrow{F_{k}}\right.$ - сила Кулона) и постоянного магнитного поля $\left(\vec{F}_{l}\right.$ - сила Лоренца). Поскольку Кулоновская сила перпендикулярна силе Лоренца, ион будет двигаться примерно по такой траектории, как на рис. 5.

При отсутсвии магнитного поля «+» ионы, которые были вблизи грани сd, давят на нее, а часть из них под действием силы Лоренца опускаются на грань ad. «-» ионы, те, что были вблизи грани ab, давят на нее, а часть из них приходится на грань аd (рис. 6) [7].

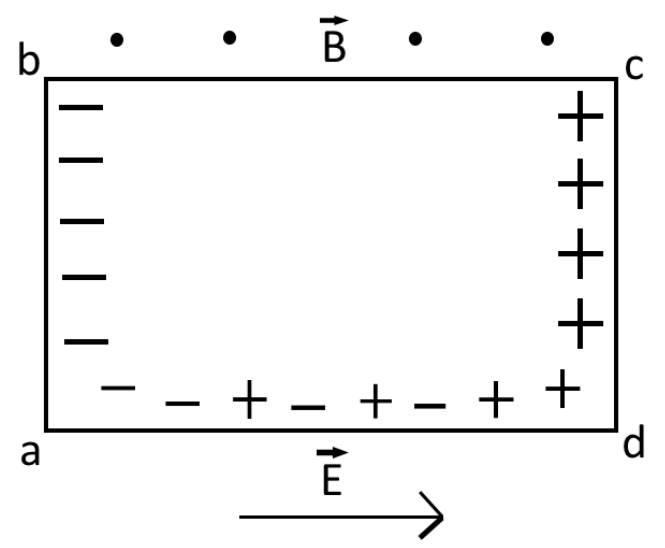

Puc. 6

Вледствие чего возникают градиенты концентрации «+» и «-» в клетке при данном направлении $\vec{E}[4]$. 


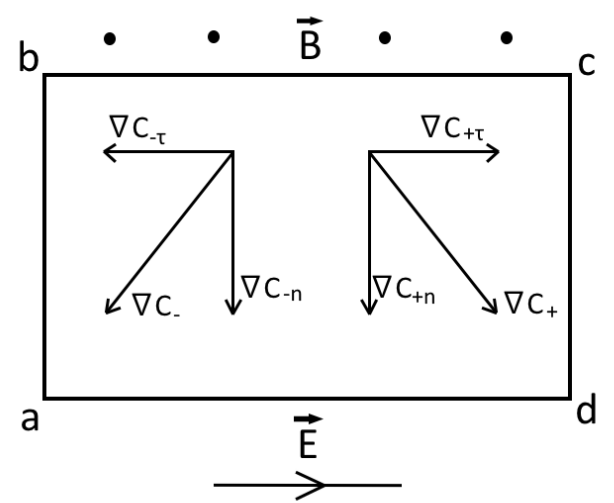

Puc. 7

На рис. 16 изображены градиенты концентрации:

- $\nabla C_{-\tau}-$ касательный градиент «-» ионов

- $\nabla C_{-n}-$ нормальный градиент «-» ионов

- $\quad \nabla C_{-}-$суммарный градиент «-» ионов

- $\nabla C_{+\tau}-$ касательный градиент «+» ионов

- $\nabla C_{+n}-$ нормальный градиент «+» ионов

- $\quad \nabla C_{+}-$суммарный градиент «+» ионов

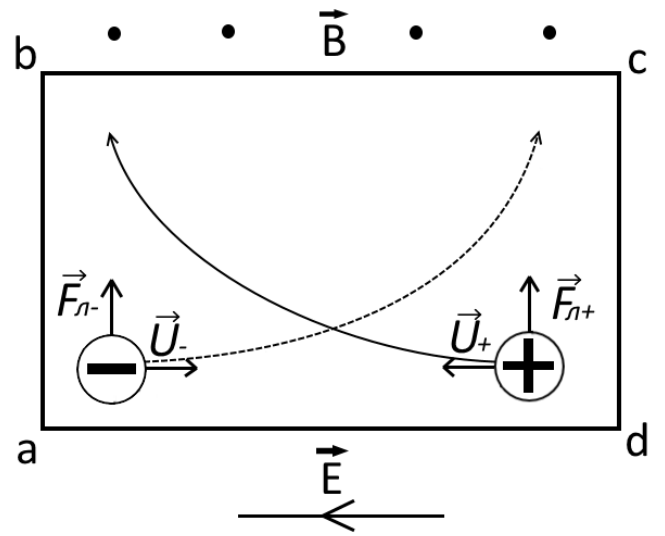

Puc. 8

Подобно процессам на рис. 5, под действием электрического поля (вектор направлен влево) возникает направленная скорость движения положительного иона влево, а отрицательного - вправо. Под действием сил Лоренца ионы движутся по траектории, показанной на рис. 8. 


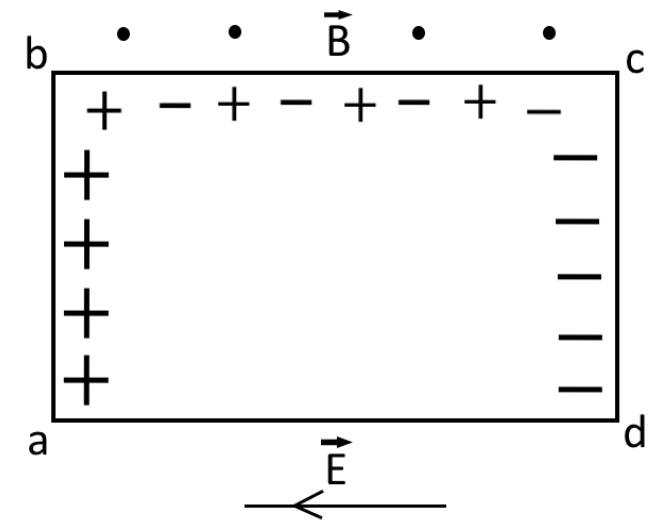

Puc. 9

При изменении направления электрического поля, при отсутсвии магнитного поля «+» ионы, которые были вблизи грани ab, давят на нее, а часть из них под действием силы Лоренца опускаются на грань bc. «-» ионы, те, что были вблизи грани cd, давят на нее, а часть из них приходится на грань bc.

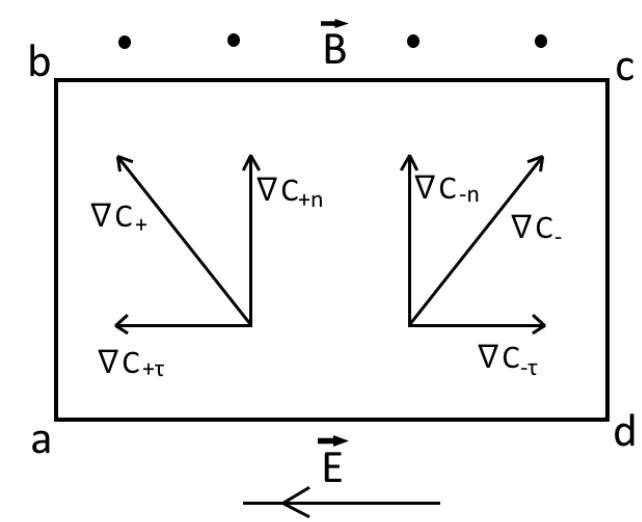

Puc. 10

Аналогично рис. 7, на рис. 10 изображены градиенты, изменившие свою ориентацию в связи с изменением направления электрического поля. Сравнивая рисунки 7 и 10, видим, что суммарный положительный градиент $\nabla C_{+}$при изменении направления эп $\vec{E}$, меняет свою ориентацию на противоположную. Подобно ведет себя отрицательный градиент $\nabla C_{-}$. При наложении магнитного поля силовое поле действует на всю внешнюю мембрану, при этом:

- «+» ион двигается по часовой стрелке

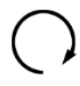

- «-» ион двигается против часовой стрелки 


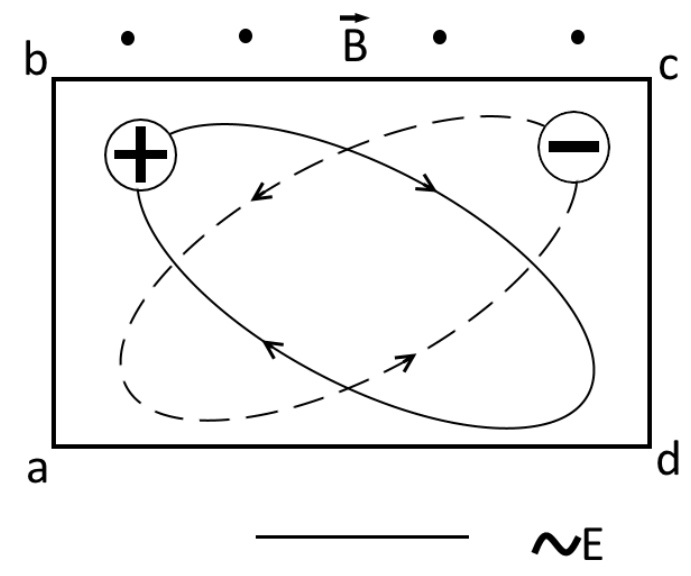

Puc. 11

\section{Суммарное движение ионов цитоплазмы за один цикл УВЧ}

Плюсы интенсификации $[8,9]$ :

- Примерно на 40 \% снижается время болевого синдрома.

- На $40 \%$ снижается время отека конечностей.

- Усиливается репарация (уменьшение времени восстановления мягких и костных тканей).

- Активизируются процессы ассоциации и диссоциации.

- Ускоряются биохимические процессы.

- Увеличивается проницаемость клеточной мембраны.

- Ускоряются процессы активного транспорта.

- Ускоряются процессы проникновения лекарственных средств внутрь клетки.

- Улучшаются процессы метаболизма и вывод продуктов метаболизма.

- Идет процесс разогревания цитоплазмы.

- Частицы цитоплазмы перемешиваются.

- Происходит силовое воздействие на все участки мембраны клетки и т. д.

Новый способ интенсификации УВЧ терапии - применение переменного магнитного поля

Помимо воздействия на клетку переменным электрическим полем [9], для усиления терапевтического эффекта используют воздействие переменным магнитным полем. Модель клетки схематично изображена на рис. 12. Клетка так же, как и раньше, рассматривается со стороны стрелки А.

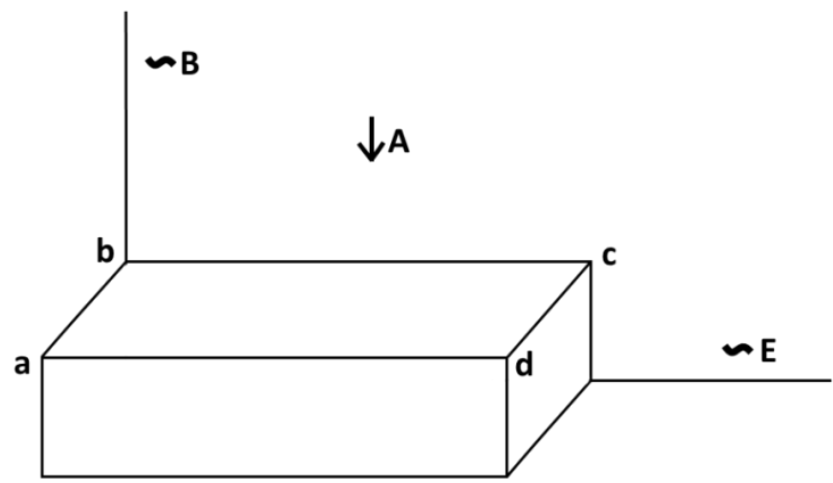

Puc. 12

Рассмотрим случай, когда линии магнитного поля направлены от нас. В этом случае на «+» и «-» ионы также будут воздействовать сила Лоренца $\left(\overrightarrow{F_{l}}\right)$, направление которой определяется мнемоническим правилом левой руки. Тогда при воздействии электрического поля, направленного вправо, «+» и «-» 
ионы будут двигаться как на рис. 13. При электрическом поле, направленном влево, ионы под действием сил изменят направление как на рис. 14.

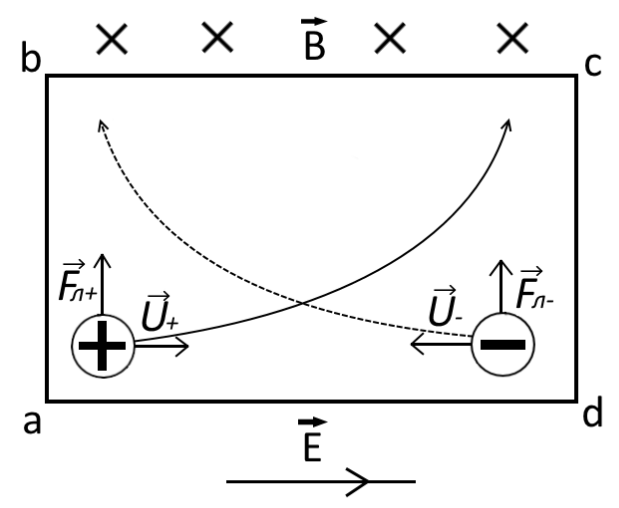

Puc. 13

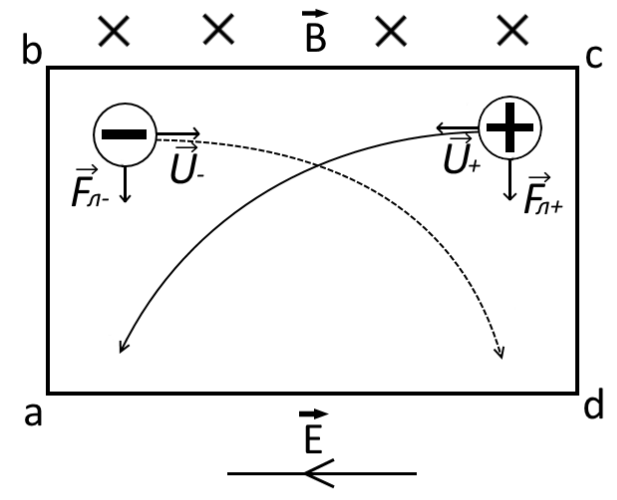

Puc. 14

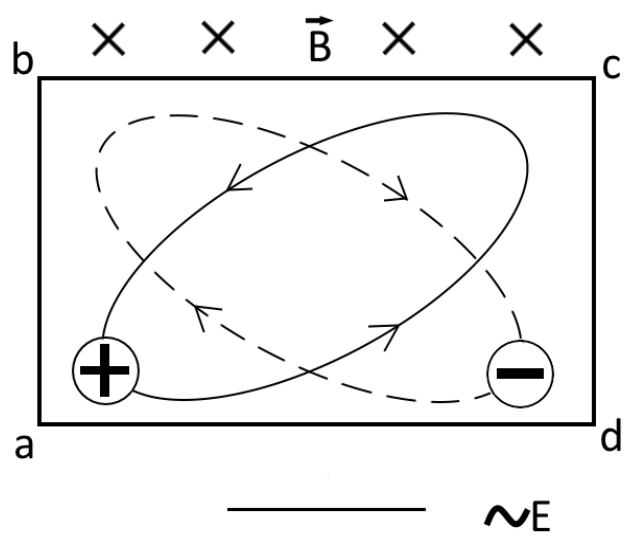

Puc. 15

Во время действия переменного электрического поля при постоянном магнитном поле, направленном от нас, как на рис. 15: 
- $\quad$ «+» ион двигается против часовой стрелки

- $\quad$ «-» ион двигается по часовой стрелке

Помимо преимуществ интенсификации, указанных выше (под рис. 11), при наложении переменного магнитного поля добавляется еще одно - усиление степени интенсификации за счет того, что положительные ионы двигаются по эллиптическим орбитам то по часовой стрелке, то против нее, а отрицательные то против часовой стрелки, то по часовой.

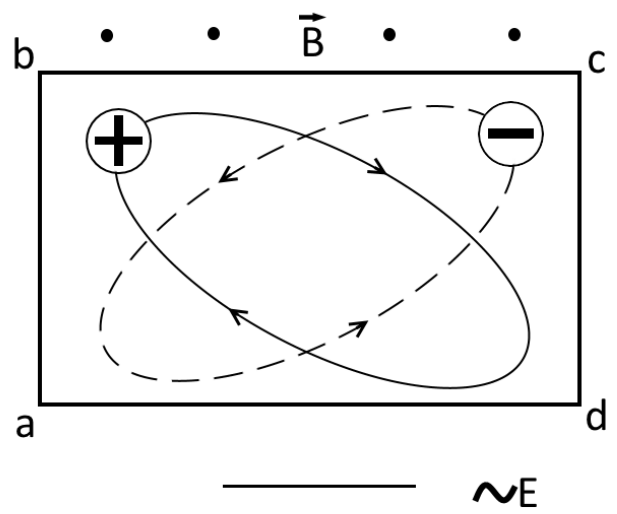

Puc. 16

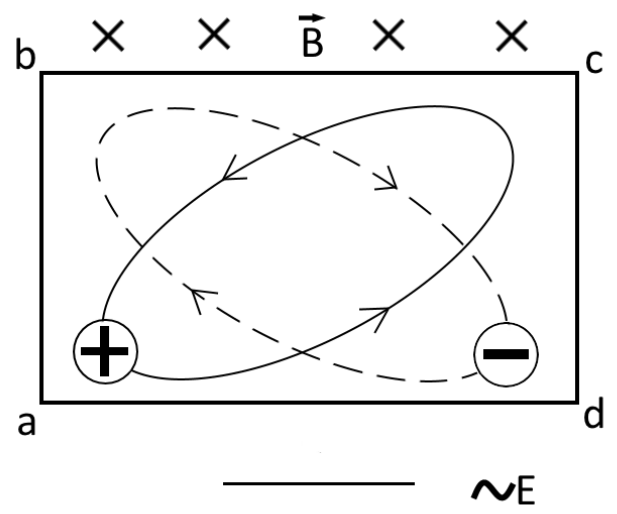

Puc. 17

\section{Лuтература}

1. Кореневский Н. А., Попечителев Е. П., Серегин С. П. Медицинские приборы, аппараты, системы и комплексы - Курск: ОАО «ИПП «Курск», 2009. - 714 с.

2. Захаров М. Ю., Захаров Ю. Б., Иванов В. Н., Овсепян А. В., Пыхалова Н. Е. Интенсификация УВЧтерапии постоянным магнитным полем // Альманах клинической медицины. - 2008. - № 17-2. - С. 186-188.

3. Пономаренко Г. Н., Турковский И. И. Биофизические основы физиотерапии: учебное пособие - М.: ОАО «Издательство «Медицина». 2006 - 140 с.

4. Филиппов E. C., Ткачук E. A. Влияние электромагнитных полей на биологические объекты // Сибирский медицинский журнал (Иркутск) - 2001. - № 1 том 24 - С. 15-18.

5. Иродов И. Е. Основные законы электромагнетизма 2-е, стереотип - М.:1991. - 132 С.

6. Трофимова Т. И. Курс физики 11-е изд., стер. - М.: 2006 - 218 С.

7. Холодов Ю. А. Магнетизм в биологии. Научно-популярное издание. - Москва: Наука, 1970. - 95 с. 
8. Пат. № 2365391 Российская федерация, С1 МПК А61N5/00 (2006.01). Способ лечения переломов костей и окружающих их мягких тканей в посттравматический и послеоперационный периоды / Захаров Ю. Б., Веселовский Ю. А., Иванов В. Н., Овсепян А. В., Овсепян В. А., Захаров М. Ю., Пыхалова Н. Е.; заявитель и патентообладатель: Государственное образовательное учреждение высшего профессионального образования «Кубанский государственный медицинский университет Федерального агентства по здравоохранению и социальному развитию» (ГОУ ВПО КГМУ Росздрава) - № 2008119306/14; заявл. 15.05.2008; опубл. 27.08.2009; БИ: 23/2010.

9. Захаров Ю.Б. Некоторые вопросы физики магнитотерапии. Материалы всероссийской научнопрактической конференции «Современные проблемы физики, биофизики и информационных технологий», Краснодар. Июнь 2010.

10. Медицинская энциклопедия [Электронный ресурс]. URL: http://www.medical-enc.ru/19/uhftherapy.shtml (дата обращения 04.02.2016). 